\title{
LXVI. On some new lines in the solar spectrum
}

\section{Professor Elie Wartmann}

To cite this article: Professor Elie Wartmann (1848) LXVI. On some new lines in the solar spectrum , Philosophical Magazine Series 3, 32:218, 499-506, DOI: 10.1080/14786444808646025

To link to this article: http://dx.doi.org/10.1080/14786444808646025

曲 Published online: 30 Apr 2009.

Submit your article to this journal

Џll Article views: 2

Q View related articles $\sqsubset$ 
Hence

$$
\frac{d^{2} z}{d t^{2}}=-\frac{d p}{\rho d z}=-\frac{a^{2} d f}{\rho d z} \cdot a^{2} \alpha\left(\theta-\theta_{1}\right) \frac{d \rho}{\rho d z}-a^{2} \alpha \frac{d \theta}{d z} .
$$

The usual theory explains how the third term of the righthand side of this equation may be in a given ratio to the first ; but my difficulty is to conceive how the same can be the case also with the second term, since it changes sign with the change of sign of $\theta-\theta_{1}$.

Cambridge Observatory, May 19, 1848.

\section{On some Nerw Lines in the Solar Spectrum. By Professor Elie WartmanN*.} THE study of the spectrum has long occupied the attention
of philosophers. As early as 1802 Wollaston made known the existence of some obscure rays perpendicular to its length. Twelve years later Fraunhofer again discovered them, and gave an analysis of them, which is a masterpiece of patience and skill. We know that he used these lines as extremely valuable marks for the construction of achromatic refractive systems. Having been sought for in spectra produced with different sources of illumination, and with prisms and absorbing media of various kind, they have likewise become of considerable interest, as affording geometricians an opportunity of discussing the comparative merits of the theories of light.

In 1840 I made a series of experiments on the spectrum with an excellent prism of flint-glass, the last cut by the illustrious Bavarian optician. These experiments led me to several results, which I communicated to my pupils and showed to some amateurs; but I desired to increase their number before publishing them in a connected form. At present, not having the apparatus which I employed any longer at my disposal, it is useless to make further delay. Notwithstanding their imperfection, I may be allowed to make known some details that I believe to be new. I extract them briefly from the note-book of my laboratory, dated April and May 1841.

"The lecture-room of the Academy of Lausanne having been darkened, a beam of solar light, thrown by a tinned or blackened mirror, was made to pass through a vertical slit of $0^{\mathrm{mm} \cdot 8}$ in width. This beam is refracted in Fraunhofer's prism fixed in a vertical position at the distance of eight metres. Directly behind this instrument is placed an achromatic theodolite of $0^{\mathrm{m}} \cdot 04$ aperture, made at Aarau, or a comet seeker

* Communicated by the Author.

$2 \mathrm{~K} 2$ 
by Canchoix, magnifying seven times, with a focal distance of $0^{\mathrm{m}} \cdot 66$, and an objective the diameter of which measures $0^{\mathrm{m} \cdot 069}$. The prism, the refracting angle of which is $45^{\circ} 4^{\prime} 20^{\prime \prime}$, is arranged in the position of minimum deviation.

"I thus discovered in the luminous field of the spectrum projected horizontally, a great number of longitudinal straight lines, some thicker than others, parallel to each other and to the length of the spectrum. They are therefore perpendicular to the transverse rays already known. They are perceptible before the telescope is drawn out sufficiently for the latier to be seen distinctly. I rarely succeeded in obtaining a view of the two systems at once. These longitudinal lines do not arise from an impurity in the prism o: in the glasses of the telescope, for they appear the same with other refracrive apparatus. Neither can they be attributed to inequalities in the rectilinear margins of the opening, nor to an imperfect state of the surface of the mirror. But their general aspect depends upon the size of the aperture, on the distance and the position of the prism, on the state of the atmosphere, on the height of the sun above the horizon, and on the hour of observation. It often appeared to me that several of them became displaced and extinguished, as if the transparency of the air bad suddenly changed. By varying the distance of the eye-glass from the objective, they are partially, if not all, changed from black into luminous lines, and vice versâ. These appearances, not having the fixity and the distinctive characters of the lines figured by Fraunhofer, must be assigned to a different cause. “'The longitudinal stripes, examined by the help of a very excellent equilateral prism by Soleil, generally appear so much the more visible as the aperture is larger. Whether it be of a circular or rectangular form is of no consequence. By removing the exterior mirror and employing direct light, the lines are seen to vary in number and position, according as the naked eye, placed immediately against the prism, moves parallel to its vertical edges*. These appearances are owing to the interference of the central rays with those which are reflected against the edges of the opening. They disappear when all reflexion is rendered impossible in this as in the prisn, and when the axis of the eye or of the glass is suitably directed. They do not change when the light of a lamp is

* 'The prism is of such pure flint, that with direct light, in misty weather, it is possible to see with the naked cyc at least sixty of Fraunhofer's lines. The two marked $B$ and $C$ in the red are perceived very distinctly; but the bundle II, and especially that which follows it in the violet, are nor clear. The experiment constantly succeeded at six motres, with an aperture of $1 \mathrm{~m} \cdot 4$. 
substituted for that of the clouds or of the sun, nor when coloured media are interposed in the passage of the rays before or after their dispersion. In short, they may be produced at will by placing one or two plain mirror's near the extremities of the aperture made in the shutter, and by giving them a horizontal inclination of variable extent, such that the brilliant image which they receive produces a spectrum which is partly superposed upon that of the direct rays. This well deserves to be made a class experiment, as a variety of that of the two mirrors of Fresnel. It is much easier, does not require any delicate or costly apparatus, and extends simultaneously to all the monochromatic zones of the spectrum.

"As the band of light which is admitted into the prism proceeds from different parts of the sky, it is eatsy to account for the changes in the appearance of the longitudinal lines according to the degree of transparency of the atmosphere. 'The modifications which this system undergoes with the changes of exterior illumination are explained by the unequal distribution of diurnal light, which, during a state of greater or less complete serenity of the air, varies with the distance of the sun from the meridian.

"These lines of interference have not been mentioned by any author, at least as far as I can learn."

In 1844, M. Ad. Erman seems to have had a glimpse of the phænomenon which I had discovered, but attributed it to the accidental defects of the vessels which he employed, and did not pay any attention to it *. It is but somewhat recently that the horizontal bands have become the subject of investigation by two experimenters, well-located for optical researches, M. Zantedeschi at Venice, and M. Ragrona-Scinà in Sicily.

M. Zantedeschi has published the results of his experiments in a separate volume, which has not yet been reviewed in France. Only a hundred copies of this work having been printed + , it will not be out of place here to give its conclusions, which confirm mine on almost every point.

" The appearance of the lines of the solar spectrum is in a necessary relation with the smallness of the aperture, and with the interval which separates the prism from it. At a constant distance the transversal lines appear with

* On the Law of Absorption of light by the Vapours of lodine and Bromine.-Comptes Rendus, t. xix. p. 832 .

+ Ricerche fisico-chimico-fisiologiohe sulla Luce; in 4to. Venice, 1846. In this the author treats of the influence of solar light on the germination of seeds, on the changes of colour produced in organic and mineral substances by the action of light alone, on a new analysis of the solar spectrum; in short, on the conversion (passage) of ponderable matter to the radiant state (?) 
the widest aperture, the longitudinal with the smallest, and the two systems with the mean one. With a constant aperture the vertical lines appear at the greatest distance, the horizontal at the smallest, and the double system at the mean distance. The angle of incidence for the transversal lines alone, is a little larger than that which gives a distinct vision of the longitudinal alone. The arrangement of the longitudinal lines varies with the distance of the prism from the aperture. The first transversal as well as longitudinal lines which begin to appear in the field of the solar spectrum, are those which, in the entire system, are the most intense and the widest. In each system the focus of the lines varies with the size of the aperture. The intensity of the luminous lines in each of the three systems is greater than that of the remainder of the field of the solar spectrum : this is what Fraunhofer discovered for the transversal lines. The state of the atmosphere modifies the focal distance of the longitudinal as well as of the transversal lines. This state alsc influences the position, number, size and force of the longitudinal and transversal lines. To each system of lines corresponds an aperture, which is best suited for its being projected most distinctly.

"Fraunhofer refers the cause of the black lines to the nature of the light. With him, the spectrum was a means of verifying the identity or diversity of the light emanating from different sources. Herschel ascribes the origin of it to the positive absence of luminous rays, whether in the act of their development, or by absorption in the media which they have to pass through. This opinion is very nearly the same as that entertained by Brewster and Erman. The former considers that the rays which are defective are absorbed by the gases produced in the combustion which engenders the light, or by the media through which they must pass, The latter is of opinion that the medium traversed by the luminous ray separates it into two or into several parts, each of which is retarded in a different manner ; on this account he distinguishes simple and double interference.

"All these opinions appear to me to be defective, although they all seem to have a true side. Fraunhofer refers the entire phrnomenon to the nature of the luminous ray alone; Herschel, Brewster, and Erman to the simple influence of the different media interposed. But in these phænomena, the apparatus itself which is used for the experiment plays an important part. It is now a well-proved fact, that the appearances of the spectrum vary with the size of the aperture and the interval which separates it from the prism, the nature and 
dimensions of this and its distance from the screen. The whole of these circumstances necessarily leads me to admit, that these appearances of the luminous spectrum are produced by the different distribution of the rays, caused by the different media which they have to pass through. The monochromatic light of the lateral spectra, the production of such different lines by the simple variation of the distance of projection, the transformation of the systems of lines into forms so varied by the alteration of size of the aperture through which the light is admitted, the increase of tints in the obscure lines, and the strengthening of the luminous ones, are, in my opinion, so many clear proofs of variations in the reflexion, refraction, and dispersion of light. I do not thereby wish to deny that any ray is extinguished by absorption or by interference, but only to show that these two acts, such as they are considered in the undulatory system, are not causes really sufficient to produce the phænomena of the luminous spectrum. It cannot be absorption; for if the black lines are really produced by absorbed rays, and not by rays differently distributed, it is impossible that the increase or decrease of the black tints should always be accompanied by an analogous variation in the intensity of the luminous lines, and the thickening or attenuation of the black lines always by the enlargement or diminution of the luminous lines. The large systems of obscure lines produced by nitrous gas and by the vapours of iodine, are traversed in their centre by a zone of very bright light three or four millimetres wide. The systems of uniform and excessively fine lines present a tranquil light, which is spread equally throughout the height of the spectrum, so as not to be remarked by an eye not accustomed to similar researches. It cannot be interference; for in the space or in the line itself, where rays which should go on increasing the intensity of light should meet, this still shows itself diminished or extinguished : the lines are sometimes luminous, white, sometimes coloured, sometimes of a more or less perfect black. I have verified this phænomenon some hundreds of times. It entirely upsets and destroys the doctrine of interference, as I shall show in a future communication, in which $I$ intend to make known the rest of my observations.

"I said that the solar spectrum is the most exquisite photoscope known. The following are some of the experiments in support of this assertion. Before the aperture, which was two millimetres wide, I placed a bottle of the purest white crystal with parallel sides. No line appeared in the solar spectrum on the screen placed at 2.39 metres from the prism. The bottle was at $0^{\mathrm{m} \cdot 1}$ from that, and the projec- 
tion of the spectrum was $0^{\mathrm{m} \cdot 16} \mathrm{in}$ length and $0^{\mathrm{m} \cdot 055}$ in height. I ought also to notice that the flat sides of the bottle were five millim. thick, and at $0^{\mathrm{m}} 043$ distant from each other. I introduced into it some crystals of iodine, which I cansed to pass slowly into the state of vapour. The bottle was placed on some sand, and it was heated by means of some incandescent charcoal placed on the sheet of iron, which sustained it as well as the sand. As soon as the vaporization of the iodine had begun, some excessively thin and ill-defined lines appeared in the field of the spectrum. By increasing the quantity of vapour, this spectrum appeared covered with thousands of longitudinal, exceedingly fine black lines; by degrees they united in a system of large and small, accompanied by some which were luminous, and at last they divided into two excessively black systems, one superior, the other inferior, separated by a zone of intense light five millim. in width. After the fire had been removed, the vapour of iodine returned by degrees to the solid state, and the two black systems weresubdivided as well as the luminous band. I have observed perfectly similar phænomena with nitrous gas. It is wonderful to see some thousands of longitudinal lines in constant motion, owing to variations of temperature*. . . I have thus convinced myself of the existence of the two following facts:-1, the internal motion of the vapours, as well as that of the translation of the vessel, produce an indescribable variety in the distribution of the black and luminous lines; 2, rarefaction of the gases causes a subdivision of the black lines, condensation unites or increases these lines. All this is in perfect harmony with the variations produced by the atmosphere. When a subtle veil of vapour suspended in the upper regions merely softens the intensity of the azure of our sky, the spectrum presents some excessively fine longitudinal lines in its field, so fine that the eye, not aware of their existence, is unable to perceive them. 'The lines marked $q$ in my figure have several times presented the phanomenon of their separation and reunion, accompanied by the successive appearance or disappearance of an interposed luminous line. These variations were observed for more than ten days, during which the state of the atmosphere constantly varied; and I have also always detected changes in the focal distance $\uparrow . "$

* The author does not appear to have paid any attention to the movements of the heated air around his prism.

+ 'Those who may consult the work from which we have translated the preceding lines, will perbaps not consider as out of place some critical notes on the chaptel' which now occupies us. In the first place, the simplified method employed by the author in order to project his lines upon a sereen, is due to M. de Haldat, who described it as early as 1838 in the Mimoires 
M. Zantedeschi's publication has induced Prof. RagonaScina of Palermo to extend this new field of inquiries. The following are some of the principal results which he has made known*. The horizontal and vertical lines may be perceived by placing a small Galilean telescope against a prism lighted by an aperture of $0^{\mathrm{mm}} \cdot 33$. The principal of them may even be seen by the naked eye. They likewise exist in the ordinary and extraordinary spectra which a doubly refracting body produces. The horizontal lines may be obtained without the help of a prism, by examining obliquely across a biconcave lens the interval which had remained bright between the two shutters of a window closed to within a decinetref. Lastly, the sy'stem of horizontal lines is submitted to an hourly periodical return, whilst that of Fraunhofer's lines is perfectly fixed. This assertion is contrary to that of M. Zantedeschi.

M. Ragona endeavours to explain the lines of Fraunhofer by attributing them to the encroachment of the four simple colours, red, yellow, blue and green. M. Zantedeschi speedily acknowledged himself of this opinion, and also explained, by the reciprocal influence of the luminous rays, his longitudinal lines $f$. This is proved, according to him, by their appearing so much the more distinct the narrower and longer the spectrum is; whilst the contrary conditions favour the visibility of

de l'Acadimic Royale des Sciences de Nancy. We know that Cooper had amnounced the existence of a visible brightness beyond the red rays (Proceedings of the Royal Society of London, vol. iv. p. 146). The Venetian Professor has not only verified the fact, but he also thinks that he has found an analogous appendage at the opposite extremity. Moreover, the discovery of an extension in the solnr spectrum, beyont the violet, is due to Sir John Herschel. He made it as early as 1819 , whilst repeating some experiments on the polarized rings with Biot's apparatus; but he did not describe it till 1840, in his beantiful memoir On the Chemical Action of the Rays of the Solar Spectrum on preparations of Silver and other Substances, in the I'hilosophical Transactions. In the $\$ 56$, entitled "Extension of the Visible Prismatic Spertrum, a new Prismatic Colour," he says expressly that there exists, beyond the violet, some luminous rays of a different colour from that of the different bands of the spectrum, and which is of a lavender-gray. M. Zantedeschi owes to the sky of Verice, which is much more propitious than that of Collingwood, the possibility of studying this extension of coloration in detail, which will no doubt be of some importance in the question of the real number of simple colours, and to which I called attention in my memoir on Daltonism (l'aylor's Scientific Memoirs, vol. iv. p. 136). Lastly, the author mentions the existence of tints of bright blue, visible above and below some prismatic zones of a horizontally projected spectrum, and he proposes calling these tints secondary spectra. But this denomination cannot be adopted, since it has for a long time been applied to the spectra produced by a prism achromatized for the extreme rays.

* Sulle righe trasversali e longitudenali dello spettro luminoso e su taluni fenomenti affini.-Raccolta Fisico-Chimica Italiana, t. ii. p. 483.

$\uparrow$ It is as well to remark, that the lens performs the part of a prism with concave surfaces, with a more or less decided curve.

\pm Raccolta, t. ii. p. 507. 
the transversal lines. Strange as may seem M. Ragona's theory, it deserves examination; but I confess that that of the Venetian Professor appears to me to be very obscure. To explain the encroachments of the coloured bands in the longitudinal direction, we must admit that the spectrum is double, and that its elements overlap at right angles. The too great brevity of the author, which is limited to the paragraph above quoted, does not allow us to suppose that such is his opinion. Moreover, these lines, fur from constituting a fact opposed to the theory of undulations, are, on the contrary, an interesting confirmation of its truth.

LXVII. Remarks on the Weather during the Quarter ending March 31, 1348. By James Glaisher, Esq., of the Royal Observatory, Greenwich*.

T the February Number of your Magazine you did me the 1 favour to insert my remarks upon the weather during the quarter ending December 31, 1847. The weather of the past quarter has been as unusual as that of the preceding, and some account of it may probably interest your readers.

The quarterly meteorological returns for the past quarter furnished to the Registrar-General have been obtained from thirty-five different places, situated between the longitudes of $5^{\circ} 18^{\prime} \mathrm{W}$. and $0^{\circ} \mathrm{i} 6^{\prime} \mathrm{E}$.; and between the latitudes of $50^{\circ}$ and $55^{\circ}$. These observations have been all rigorously examined and reduced by myself, and their results are worthy the attention of meteorologists. The following are the particulars of the weather during the quarter ending March 31, 1848.

The weather during the past quarter has been remarkable in many respects. The daily temperature of the air has for the most part been above the average, yet there was a period of exceedingly cold weather between the 20th and 28th of January ; the departures from the average on the $26 \mathrm{th}, 27 \mathrm{th}$, and 28 th, were $12^{\circ} \cdot 8,10^{\circ} \cdot 8$, and $16^{\circ}$ respectively. The temperature then suddenly increased to $6^{\circ} \cdot 5$ above the average on the 30th; and for the most part the daily values afterwards exceeded those of the average, or differed very little from them.

It may perhaps tend to clearness if I speak of each subject of investigation separately.

The mean temperature of the air at Greenwich-

For the month of January was $34^{\circ} \cdot 6$, which is $1^{\circ} \cdot 7$ above that of $184.2,4.5,3^{\wedge} \cdot 7,9^{\circ} 1$, and $0^{\circ} .5$ below those in the years 1842 to 184.7 respectively; or it is $3^{\circ} .8$ below the average of these six years.

- Communicated by the Author. 